\title{
Impact of renewable energy in Indian electric power system
}

\author{
V. Saravanan ${ }^{1}$, K. M. Venkatachalam ${ }^{2}$, M. Arumugam ${ }^{3}$, M. A. K. Borelessa ${ }^{4}$, K. T. M. U. Hemapala \\ ${ }^{1,2,3}$ Department of Electrical and Electronics Engineering, Arunai Engineering College, Tamil Nadu, India \\ ${ }^{4,5}$ Department of Electrical Engineering, University of Moratuwa, Moratuwa, Sri Lanka
}

\begin{tabular}{l}
\hline \hline Article Info \\
\hline Article history: \\
ReceivedAug 19, 2020 \\
Revised Jul 9, 2021 \\
Accepted Jul 23, 2021 \\
\hline
\end{tabular}

Keywords:

Electric power system

Impact studies

Photovoltaic

Renewable energy

Wind system

\section{Corresponding Author:}

\begin{abstract}
This paper addresses the impact of renewable power generation such as photovoltaic and wind energy in the existing power system operations. Various modeling approaches and power quality/reliability analysis of these renewable energy sources in the electric power system by researchers and research organisations and utilities are outlined and their impacts are assessed. Challenges and protection schemes of renewable power integration into the existing grid are discussed through a detailed literature review and study of renewable integration into the Indian power system are outlined including potential planning and policy actions to support renewable energy integration in India.
\end{abstract}

This is an open access article under the CC BY-SA license.

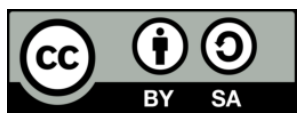

\author{
V. Saravanan \\ Department of Electrical and Electronics Engineering \\ Arunai Engineering College \\ Tiruvannamalai 606 603, Tamil Nadu, India \\ Email: vsaranaec@yahoo.co.in
}

\section{INTRODUCTION}

India's clean energy transition is continuing at an accelerated pace, with commitment, vigour, and a clear focus on non-fossil based generation, self reliance, climate action, technology advancement, economic growth, and energy security. The country's installed renewable energy capacity has crossed 100 gigawatts (GW) (excluding large hydro), showcasing remarkable progress towards India's goal to deploy $450 \mathrm{GW}$ of renewable energy by 2030 .

Electric power infrastructure of a country comprises of thermal, hydro, nuclear, and renewables resources based power generation, driven by key principles such as reliability, security, economy, and adequacy. Operating the electric infrastructure based on these principles ensures the end users a high quality/economic power supply. Growth of renewable power generation (RPG) can be achieved especially through solar and wind augment these principles through various attributes like rich natural resources, technical advancements, policies, low carbon emissions, and economic/environmental protection.

Wind and solar photovoltaic power output is influenced by weather and climatic conditions. Renewable power integration in low/medium voltage distribution network at higher penetration level can cause reverse power flow, energy demand, network congestion, voltage rise/fall, transformer overloading, and other operational issues. A key challenge in integrating RPG is to find various approaches to ensure safety and stability of power grid to provide long term sustainability and economic profit to the power systems. RPG penetration capacity into the grid can be analyzed through studies like demand response characterization, power quality (PQ), and reliability assessment (RA). 
Small scale renewable energy generation at unity power factor incurs additional cost for the utility in providing required reactive power. So large renewable power plants are suggested which have effective real and reactive power flow along with regulated voltage control with better power factor. The level of renewable power penetration in any power system depends upon load type and profile, weather conditions, feeder power handling capacity, network parameter, system topology, and its connection types (three or single phase).

To overcome the problems, various researchers have analysed the impact of RPG on electric power system, which involves many steps. First, obtain an accurate model of power system, including detailed models ofvarious renewable energy systems, load consuming pattern and their characteristics (demand response). Followed by various methods to evaluate the power quality and reliability assessment and suggestion of corrective solutions through experimental study cases.

\section{LITERATURE REVIEW}

The literature review is presented in two sections addressing the modeling and performance evaluation of RPG integration into the exiting power system having alternating current/direct current (AC/DC) transmission/distribution networks discussing about different methods of modeling and performance indicators, load classification, price calculations, real and reactive power flows, voltage/frequency regulation, power inverters, protection schemes, use of internet of things (IoT) concepts, PQ indices and reliability assessment through case studies and utility experiences in different countries of the world with feasible solutions.

\subsection{Based on modeling of renewable energy integration in the power system network}

Nikolaev et al. [1] had developed Monte Carlo method based probabilistic power flow algorithm to evaluate the performance of renewable energy sources in the electric power network. Wang et al. [2] had employed the usage of decision treeapproach for power system incorporating renewable energy generation with the help of wide area measurement system (WAMS) to ensure stability. Ju et al. [3] had proposed stochastic averaging method to analyze the uncertain variability on power system dynamics due to integrating renewable energy and electric vehicles into power system. Zheng et al. [4] have made stochastic optimization analysis of cost risk for integrated renewable energy system with less computational burden.

Tao et al. [5] have reviewed the evaluation of IoT attributes in power system for providing access to affordable, clean/green energy worldwide through the use of smart devices. Jiang et al. [6] have reviewed the development of distributed photovoltaic (PV) in electricity market and summarized three main trading modes of distributed PV market such as direct participation, aggregation and decentralized transactions and analyzed bidding strategies/corresponding models for different trading modes. Allella et al. [7] have realized a simple dynamic model with inertia stochastic process for RPG's contribution to the total power generation, tested under different scenarios including contingency/post contingency events for longer time periods. Hlalele et al. [8] presented a multi objective dynamic economic dispatch model with renewable obligation requirements to maintain the continuity of supply and its performance is tested for IEEE 24 RTS/IEEE 118 bus system through numerical simulations.

\subsection{Based on performance evaluation and its implications of renewable energy integration in the power system network}

Lennerhag et al. [9] had studied performance indicators such as, disturbance levels of slow voltage variations, overloading, harmonics, flicker, rapid voltage changes, losses, or the number of certain power quality events in the network which can be used for evaluating the impact of renewable energy on power systems. Asadinejad et al. [10] had suggested that electricity consumers should be classified and segregated based on demand response and volatility of prices under high renewable penetration which results in minimum technological and economical losses. Vilchez and Stenzel [11] had assessed power quality issues in renewable energy generation such as voltage sag, flicker and harmonics in the existing electrical power systems. Duong et al. [12] had checked the impact of distributed generation penetration into the IEEE 9 bus power system through electrical transient analyzer program (ETAP) simulation, having PV and wind power plants. Type, location and selection of RPG with respect to availability play a vital role during its integration into the grid.

Perdue and Gottschalg [13] have observed the failure rates of small grid-connected photovoltaic system. The key findings of the study are average system lifetime yield and reliability get increased, due to close monitoring of the system for various maintenance regimes. Voulis et al. [14] had simulated the performance of renewable energy integration (REI) in three representative urban areas in Amsterdam, which 
requires locally tailored approaches with coordinated storage and obtained positive results to support REI in future distribution grids with the help of four metrics.

Sun et al. [15] have described the necessity for renewable energy power fluctuation mitigation due to the events like low frequency oscillation and cascading failure. They also suggested few strategies/algorithms to suppress the output fluctuation of renewable energy through filtering, moving average, discrete Fourier transform, kalman filtering, empirical mode decomposition, wavelet/wavelet packet decomposition, model predictive control, and other algorithms. Wangdee [16] have employed well-being analysis framework for power system reliability during wind energy integration into the existing power system. Some important challenges related to technical/environmental/socio-economic aspects at increased renewable penetration are discussed by Chen et al. [17].

Meyer et al. [18] have surveyed the utilities experiences on various power quality issues resulting from the penetration of solar power in the existing utilities. The survey raised questionnaires dealing with PQ of PV installations and found lack of information among utilities/network operators and they recommended to intensify the monitoring of PV installations for its PQ assessment. Zhao et al. [19] had investigated techno-economic aspects of RPG penetration in the existing power system through nodal indices method and suggested that the consumer should choose renewable generation with improved reliability at expected price. Hu et al. [20] had studied the reactive power requirements needed in distributed energy resources energized power system having the features of voltage and grid stability. They checked the performance of different type of reactive power equipments needed for RPG in the existing power system through simulation and assessed with relative available transmission capacity index with case studies.

Ritik et al. [21] had studied the impact of frequency regulation and deviation aspect in wind power penetration in the existing power system after system events. They observed the wind power penetration in the grid to reduce the system inertia and increase of droop behaviour. Aik and Andersson [22] had proposed a classical analytic model of single and multi-in feed line commutated high-voltage direct current (HVDC) system incorporating renewable resources to realize steady state voltage stability in the weak AC/DC systems. Aziz and Ketjoy [23] have explained the effect of voltage violation happening in the medium voltage grid, when PV penetration exceeds certain threshold level withoperational rules of thumb. Aziz and Ketjoy [24] have tested the impact of PV penetration with five different configurations for multiple voltage rise mitigation techniques through a case study suited for rural area low voltage (LV) network of Thailand. They had observed that higher amounts of PV generation could be tolerated by LV networks due to many reasons, such as a wider voltage tolerance band, larger conductor diameters, and moderate lengths of feeders in the existing network and suggested the level of PV penetration can be further increased by using on load tap changer, reactive power control and partial network upgrading which are found to be cost effective for voltage control.

Gao et al. [25] have proposed a zonotope based set theoretic method for quantifying the renewable power fluctuations in hybrid AC/DC distribution network. Ustun et al. [26] had studied the impact of smart inverters of PV system on the distribution networks in terms of voltage rise/drop profiles, reverse power flow, VAR injection with respect to feeder. Matevosyan et al. [27] have discussed about various challenges such as reduced system strength, synchronous inertia, and black start capability associated with renewable energy based inverters in the existing power system.

Kroposki et al. [28] have predicted that by adding more solar and wind power generation into the power systems, soon the future grid will be inverter dominated grid. Sun et al. [29] had identified system challenges and opportunities for the development of future grid in support of China's national energy policy that emphasizing the use of clean energy. They also discussed the penetration of renewable energy into China's electric grid and highlighted the importance of HVDC technology for power transmission due to its geographical availability with the help of developments in power electronics having the features like fast control dynamics and sensitivity to fault.

Blaabjerg et al. [30] have investigated the role of RPG in power grid and associated protection issues such asfault current contribution, reduction in reach of impedance relays and auto reclosure. RPG protection is enhanced by quick fault identification and isolation with little human intervention. Different protection schemes such as voltage/over current/differential/distance/adaptive protection and fault current compensation are employed in RPG integrated power system, operating either in the islanded or gridconnected mode.

Cárdenas and Menendez [31] have explained the role and implementation of industrial IoT in RPG integrated power system, which introduces new challenges and more intelligent asset monitoring. Remon et al. [32] have explained PV penetration and their control in the system is evaluated by studying the stability of the system with DIgSILENT power factory with respect to line, load and generator contingencies. Guo et al. [33] have carried out short term reliability assessment method based on the time varying probability ordered tree screening algorithm for islanded microgrid operation having renewable energy resources to its maintain 
stability and security. This study is verified through MATLAB simulation for European low voltage microgrid system.

Johnson et al. [34] have investigated the impact of distributed energy resources (DER) are controlled by an adversary and observed the various anticipated power system risks from adversary control of DER aggregations, assessed for each grid support function and also suggested solutions to minimize common mode vulnerabilities. Acevedo et al. [35] have presented visualization approach for enhancing analyses of renewable integration impact assessment by Midcontinent independent system operatorin the U.S. Midcontinent, which uses tools data analytic process for studying renewable integration issues. Feng et al. [36] have evaluated capacity credit of RPG in smart distribution systems and analyzed its performance on IEEE-38 bus distribution system at different penetration levels of RPG, considering the impacts of demand response.

Fan et al. [37] have analyzed the impact of RES into power system through demand response approach and presented the impact of demand response/comfort loss tolerance on integrated RES. Liang et al. [38] have suggested an aggregated model for distributed energy management through crowd sourcing behaviors and validated the same by numerical studies by analyzing market performance and energy sharing.

Ustun and Aoto [39] have analyzed the behaviour of smart inverter on the distribution network operation having PV based power system under different operating conditions through a novel software namely solar resource application platform for grid simulation (SoRA-Grid) in MATLAB platform. Westacott and Candelise [40] have assessed the impacts of photovoltaic penetration in the LV distribution network by analyzing through a novel geographical information system framework which is capable of identifying the areas to facilitate further PV deployment.

Lupo et al. [41] have analyzed the effect of increasing renewable capacities in Great Britain, by determining spatial distribution of RPG expansion and demand and electricity wholesale market price effects and determined the cost of the transformation path and its influence on the British electricity prices. Liu et al. [42] have laid out the prospects for research on key technologies such as structural morphology prediction of AC-DC hybrid systems, exploring AC-DC coupling interaction, uncertainty modeling, operation simulation, improving model solution algorithm, and comprehensive scheme evaluation. Wei et al. [43] had studied the impact of energy storage (ES) on economic dispatch of distribution systems and obtained optimal value function to provide reference for ES sizing to quantify the economic impact of ES unit on distribution system.

Kuwahata et al. [44] have made renewable integration grid study for the 2030 Japanese power system in terms of frequency stability, economically optimized dispatch, demand response, ancillary services and power flows for higher renewable energy (RE) penetration into the grid. Jie et al. [45] had studied the impact of renewable energy balancing power in Japanese power system with increase in the use of wind and solar power generation having automatic generation control standard model. Gihan et al. [46] have proposed kernel density estimation for analyzing the impact of increasing wind and solar generation to calculate system reliability indices through case studies.

Huang et al. [47] have studied the reliability and economy assessment of offshore wind farms, considering various topological structures and their investment costs to suggest preferential choice for wind farm construction. Chen [48] had worked out theoretical and quantitative analysis of integration of distributed energy resources (DER) and the corresponding market power effects on utility corporation's profits and market prices. Numerical studies of this approach has demonstrated the impacts of with holding strategies and the integration of DERs. Krpan and Kuzle [49] had studied the impact of frequency response with huge share of wind generators in the power system through simulations with few test cases. Kumar et al. [50] had investigated the stability impact with high PV penetration in Texas 2000 bus network under transient conditions, and observed the voltage and frequency stability of the system.

Liu et al. [51] analyzed the increased level of RPG integration in power system leads to transient stability and out-of-step tripping protection for a modified two-area test system and Great Britain 29-zone system using DIgSILENT power factory. Bajaj et al. [52] presented an analytic hierarchy process for PQ assessment through unified power quality single index (UPQI) within the entire distribution network (DN) having RPG and verified on IEEE-13 bus test distribution system in MATLAB/Simulink environment to assess the overall PQ performance of each of the buses and the entire DN with respect to the threshold level of unity. Bhamu and Bhatti [53] have developed state-space model for their power system model interconnected to the system to ensure stable operation to maintains active and reactive power balance of RES. Hirase [54] have analyzed the grid supportive functions in grid tied inverters with RPG with a detailed guideline based on stabilization/disturbance theory, needed for the system administrator.

Wang et al. [55] have made risk assessment method in power distribution networks to integrate large scale distributed PVs and obtained comprehensive risk indicator for system evaluation through simulation for IEEE 34-bus system for reducing load fluctuations and number/capacity/location of access 
points for PV sources. Su et al. [56] have assessed the distribution network reliability during the integration of PV power along with the failure of PV power equipment due to aging, degradation rates and time-varying islanding operation. They also suggested few novel reliability indices which have more sensitivity and accuracy for the reliability assessment of a distribution network topology in China

\section{IMPACT OF RENEWABLE ENERGY PENETRATION ON POWER SYSTEM PLANNING}

The impact of renewable energy integration in the power system planning deals with balance of RPG portfolio with respect to the variability of the load to ensure reliability with high renewable capacity addition through propoer generation, transmission and distribution planning process. The renewable power generation should be amenable to follows its own daily and seasonal patterns, in accordance with the net load. The power system load curves should be associated with the RPG portfolio, which should be dispatched daily to serve the load by understanding the fuel mix of the system to minimize the overall costs with different levels of predicted load. RPG is characterized by its load-following at regular intervals and frequency regulation capabilities supported with design of efficient markets, accurate day-ahead renewable resource forecasting, resource data collection and extraction. In transmission planning model, transmission infrastructure to deliver power from the generators to the loads is carefully examined and time domain simulations are performed for many operational contingencies. Finally, the distribution planning accounts a variety of weather conditions that affect loads operating at widely varying spatial topologies at different voltage levels and diverse system equipment. Peak load calculation and use of automated tools for screening RPG installations will become necessary to the existing distribution systems becomes necessary. Feeder voltage regulation, fault current and protection desensitization should be examined and corrected by using on-load tap-changer in the substation and self-commutated inverters on a case-by-case basis.

\section{HOW HIGH DOES LEVELS OF WIND AND SOLAR IMPACT THE GRID?}

Wind and solar energy penetration in the grid can be easily doneby assuming the following changes which could be made over a period of time: a) increase balancing area cooperation, b) increased use of subhourly scheduling for generation and interchanges and transmissionexpansionto accommodate RPG, c) coordinated commitment and economic dispatch of generation over wider regions, d) appropriate wind and solar forecasts in unit commitment and grid operationsto provide down reserves, e) increase in the flexibility of RPG and commit additional operating reserves.

Solar photovoltaic generation integrated in the distribution system have the impacts [57], [58] such as reverse power flow, voltage rise and fluctuations, interactions with on-load tap changing transformer (OLTC), reactive power compensators, power quality, over current and overvoltage protection coordination, and modification of feeder section loading. The scope of this study also includes: a) identification of local and/or system wide impacts of RPG on the power distribution grid, b) guidelines and best practices to meet expected impacts as a function of the penetration level of RPG, c) mitigation measures for any contingencies, d) PV inverter performance tests for different vendor-specific devices. National Renewable Energy Lab. (NREL's) technical report on high penetration PV distribution [59] classifies the impact levels interms of overload, voltage, reverse power flow, system protection, and contingency conditions.

\subsection{Model based study for assessing PV impacts}

Two important aspects of model based study for assessing PV impactsare: a) development of system models and necessary data for time series analysis, and b) performing the analysis to understand the impact of adding PV to the electric grid. These models are also based on planned changes in the network topology, faster control equipment, load forecasting, and new distributed energy resources. Figure 1 shows a flowchart of the basic steps of PV model development.

\subsection{Development of a base case model for PV impact assessment}

For effective PV impact assessment, the first step is to develop an accurate model of the distribution circuit integrating the PV system, then adding all other components such as LTC transformers, voltage regulators, capacitors, breakers, reclosers, fuses, sectionalizers, switches, and control parameters, including time delays and dead bands with their characteristics and location. Customer load and PV generation models with respect to selection of PV inverters, priority setting of smart PV inverter operations dealing with low/high voltage ride through, volt-watt/volt-VAR control, including time-varying representation should also be accounted in this model.

Power flow analyses are performed repeatedly to assess the impact of PV equipment in the distribution system in terms of of voltage and thermal loading and loss of PV generation with/without feeder 
operations. Various mitigation techniques for high penetration PV impacts are influenced by PV inverter operation capabilities such as power factor operation, reactive power compensation, dynamic voltage control, and priority setting are carried out after assessment. Figure 2 explains various steps of performing a PV impact study.

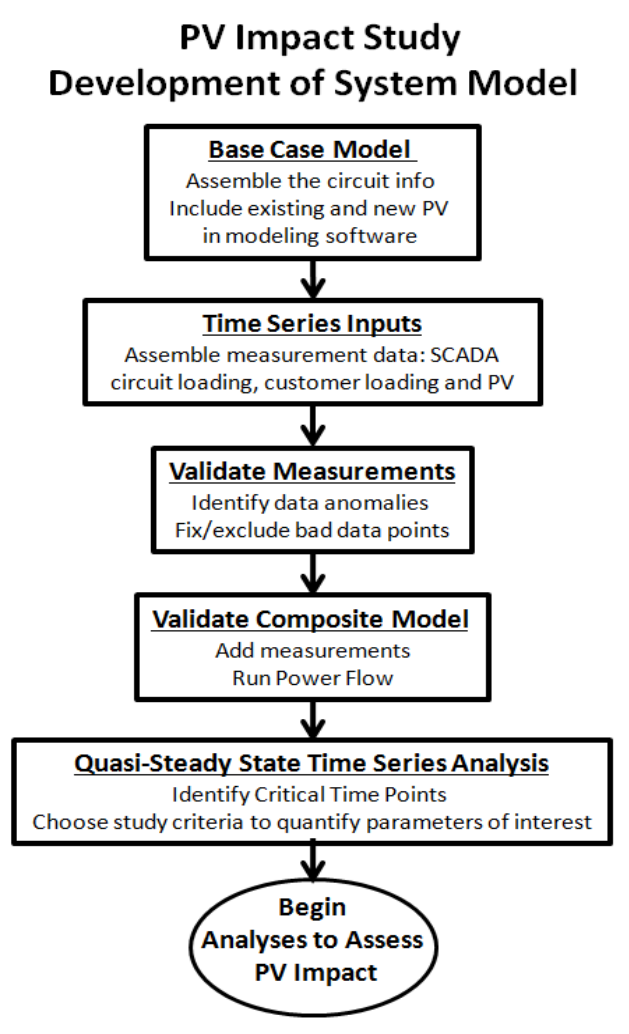

Figure1. Flowchart for PV model development

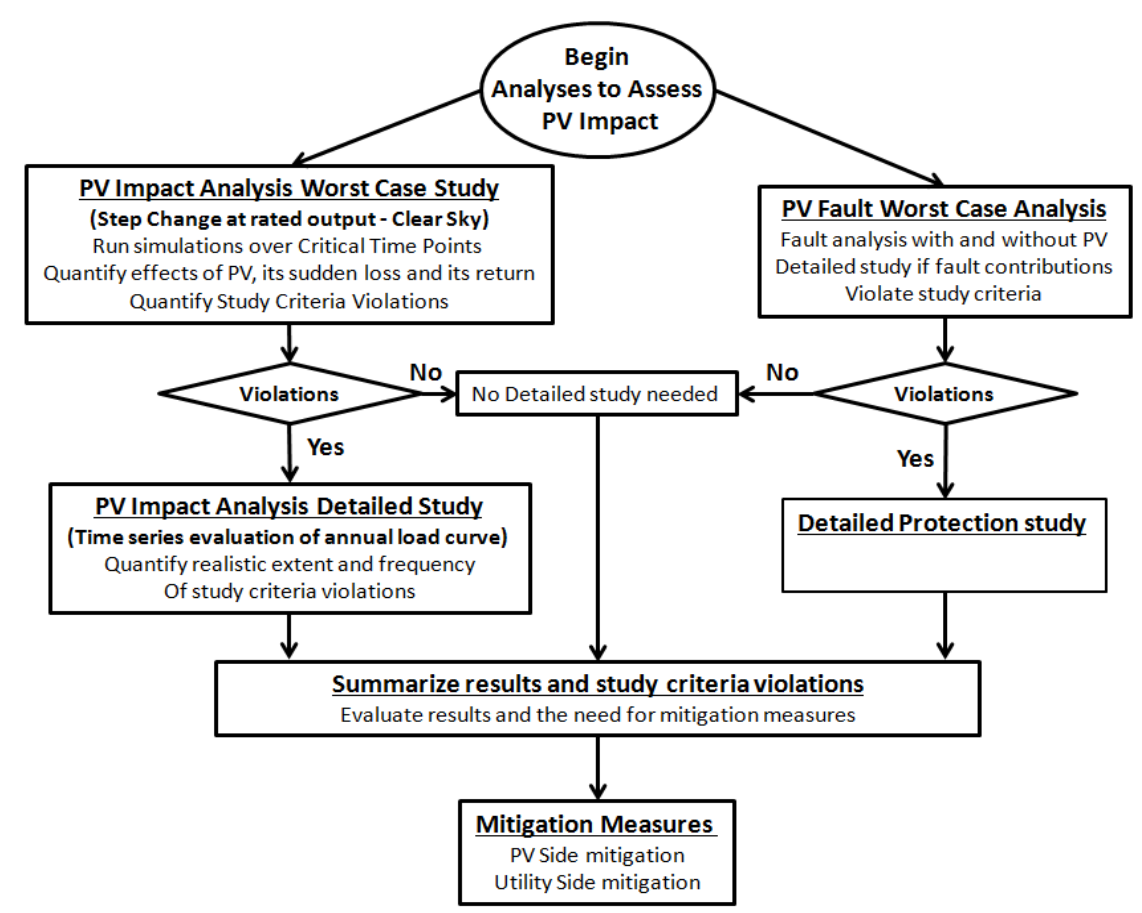

Figure 2. Flowchart for performing PV impact studies 
Drivers and barriers influencing renewable energy transition: The key drivers are increasing public awareness of climate change and the need for mitigating action, sustained reduction in the cost of renewables, technological progress, new markets and business models and energy security. Significant barriers are changing public regulations creating an unstable investment landscape, rigid requirements leading to costly supply chains, lack of digital mindset and digital technology skills, access to adequate infrastructure and shifting away from the oil, gas and coal industries.

Drivers and barriers influencingthe transition from a power grids perspective: The key drivers are the need for renewables integration, system expansion to deal with load growth, digitalization to enable the management of decentralized resources, data and information energy trading between multiple stakeholders and energy security. Significant barriers are: lack of appropriate utility business models and the fear of stranded investments, lack of collaboration between stakeholders, insufficient interoperability of HVDC systems, massive investment and workforce skills.

The following points should be considered for renewable energy transition are: a) active and proactive power system development and operations, b) hybrid generation for optimization, c) strengthened cyber security governance, cyber security practices, protecting personal data, and build cyber security capability, d) harness and develop the power of digital technology, e) develop and diversify the business portfolio in different business segments and geographies, f) financial discipline and flexibility to grow, maintain and re-invest, and g) develop an agile, digitally adept and sustainable workforce.

\section{BRIEF OVERVIEW OF THE INDIA POWER SYSTEM}

India's total installed generating capacity is around $388.133 \mathrm{GW}$ as on August 2021, which comprises of $234.258 \mathrm{GW}$ of thermal, $46.412 \mathrm{GW}$ of hydro, $100.683 \mathrm{GW}$ of renewable and $6.78 \mathrm{GW}$ of nuclear generation [60]. The country's electric grid is demarcated into five operating regions as shown in Figure 3, and its peak power demand is expected to increase to $520 \mathrm{GW}$ in 2036-2037. India committed to United Nations Paris Agreement on climate change to meet the power generation capacity with renewable energy sources through various policy mechanisms and operational infrastructure.

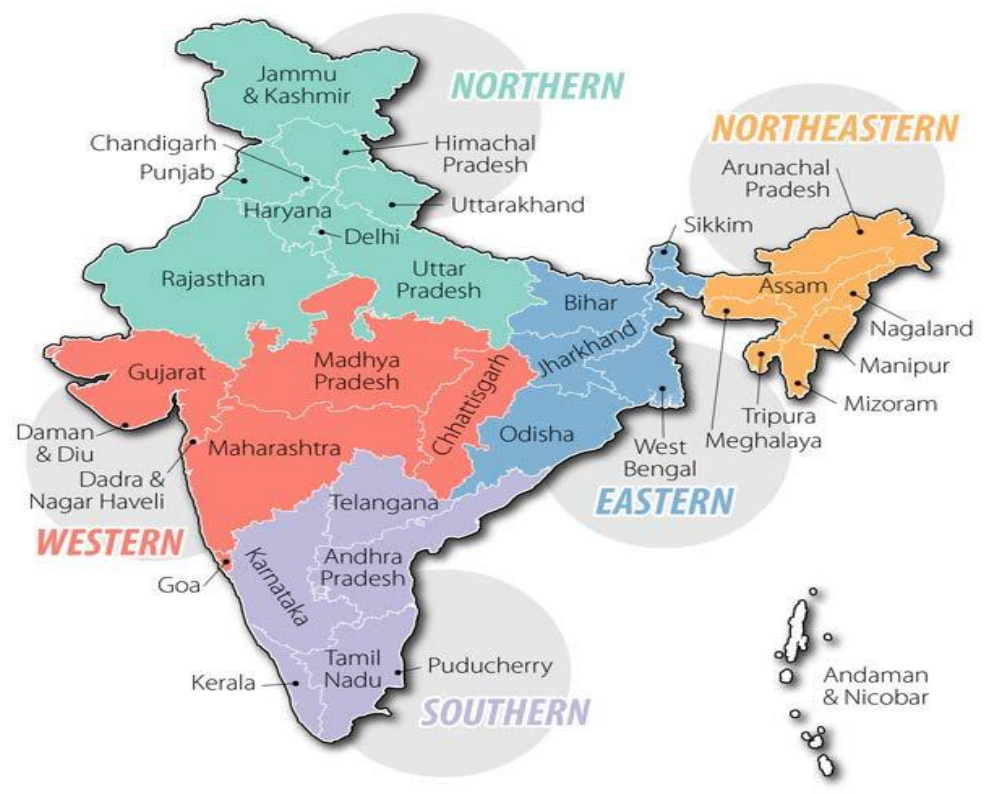

Figure 3. Indian electricity grid-five operating regions

\section{PATH WAYS FOR RENEWABLE ENERGY INTEGRATION IN INDIAN POWER GRID, STUDIES CONDUCTED BY NATIONAL AND INTERNATIONAL ORGANISATIONS}

Government of India (GoI) have set a target of acheiving $175 \mathrm{GW}$ from RE by 31 December 2022 and $40 \%$ of electricity capacity addition through RE (i.e ) $450 \mathrm{GW}$ by 2030 by increased deployment of wind and solar capacity, supported by rapid changes in technology costs and performance factors. Increased deployment of RPG needs a new dimension in power system planning with respect to optimal siting of generation capacity, tradeoffs between generation and transmission infrastructure, and system flexibility 
needs. GoI have focused towards clean energy transition to cater future energy demand in more sustainable and responsible manner, while meeting its global commitment towards climate action.

Cost effective action plan is suggested for the operation of Indian power system through various operational strategies like shifting from a thermal power generation to renewablebased power generation, additionalinvestments in PV based RPG and increased use of battery energy storage system (BESS). To achieve least cost pathways for India's electric power sector, an action plan is suggested for the operation of Indian power system which are based on: a) shifting from a thermal-based system to a renewable-based system, b) by having additional investments in new capacity with respect to variable renewable energy (VRE) and demand, c) use of BESS, d) Increased PV based RPG. To integrate $175 \mathrm{GW}$ of RE into India's power system by the year 2022, power system planners uses weather/power system modeling (both national and regional) for meeting renewable energy targets and evaluatessuitable actions favorable for grid integration. National model employs production cost model which finds optimal scheduling and dispatch of available power generation to manage the variability and uncertainty associated with integrating of RE. The national model [61] evaluates major energy flows across the country and role of coal-dominant states with less RE potential to facilitate system balancing. The national model is based on day-ahead scheduling with respect to site-specific RE generation forecasts, economic dispatch on 15-minute operational timescale, transmission flows between states, operational/technical/commercial features of each available generating resource and its practices.

Regional model includes intrastate transmission details used to investigate power system operations in each of the states for significant growth in RE capacity. This regional modelincludes all transmission lines and substations within each of the states, to provide robust view of localized operations which can offer more relevant insight to support state-level planning. National model checks a larger number of scenarios and strategies in short run time, whereas high-resolution regional model ensures better computational efficiency and provide thoughtful insights for policy makers to assess the impact of in-state transmission constraints on system flexibility and analyse the impact of RE site selection/state-level transmission planning on RE curtailment through various RE integration strategies which can impact the operations of conventional/ RE generation at the state level. Renewable energy supply curve including wind and solar are used to characterize the potential sites available for RPG deployment and evaluate its fesibility through detailed weather data, geospatial constraints, and economic assumptions which are presented in Figure 4.

NREL grid integration studies [62] have affirmed the technical and economic viability of integrating $175 \mathrm{GW}$ of RE into India's electricity grid by 2022. The two-volume study report titled, "Greening the grid: pathways to integrate $175 \mathrm{GW}$ of renewable energy into India's electric grid vol. 1, national study and vol. 2, regional study gives details, how India's electricity grid can manage the variability and uncertainty of RE target of $175 \mathrm{GW}$ by 2022, which uses advanced weather and power system model to explore its operational impact and identify possible favorable for integration.

This work is conducted by an initiative co-led by Ministry of Power, GoI, and U.S. agency for international development under the U.S. India strategic clean energy partnership 2030 and World Bank's energy sector management assistance program. This team comprised a core group from the power system operation corporation limited, national renewable energy laboratory, and Lawrence Berkeley national laboratory, and central electricity authority, powergrid (the central transmission utility), and various state load dispatch centers. This study addresses two critical challenges such as: a) enabling conventional thermal plants to flexibly generate electricity and b) increasing power grid balancing areas.

The national study of the report (vol. 1) uses a production cost model based on optimal scheduling and dispatch of available generation to minimize the total production costs subject to physical, operational, and market constraints on a 15 minutes interval. To investigate system operations in each of the states with the potential for significant growth in RE capacity in the country, this study also uses a higher-resolution regional model (vol. 2) that includes intrastate transmission details.

Results of the study provides excellent operational performance of these national/regional models to integrate $175 \mathrm{GW}$ of RE by the year 2022 through national/regional corordination and scheduling strategies with enhanced power system flexibility with existing coal reserves, year round generation-demand balancing for every 15 minutes period of 2022 with better cost savings.

Power system balancing with $175 \mathrm{GW}$ of RE is achievable with minimal integration challenges, reduced fuel consumption and emissions by meeting regulatory targets, expanding transmission in strategic locations, and planning for future flexibility and reliable operation of the power system. Figure 5 shows the impact of RE integration strategies on production costs and RE curtailment. 


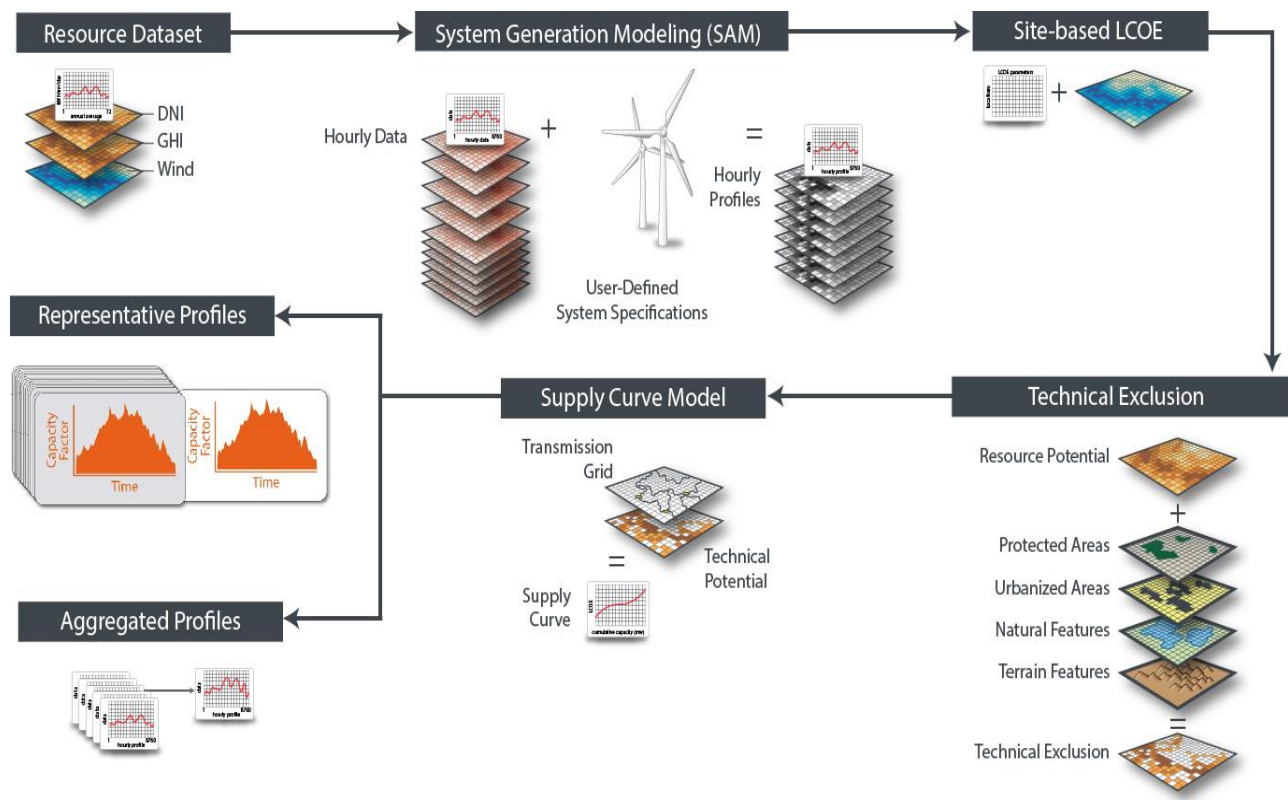

Figure 4. Renewable energy supply curve model

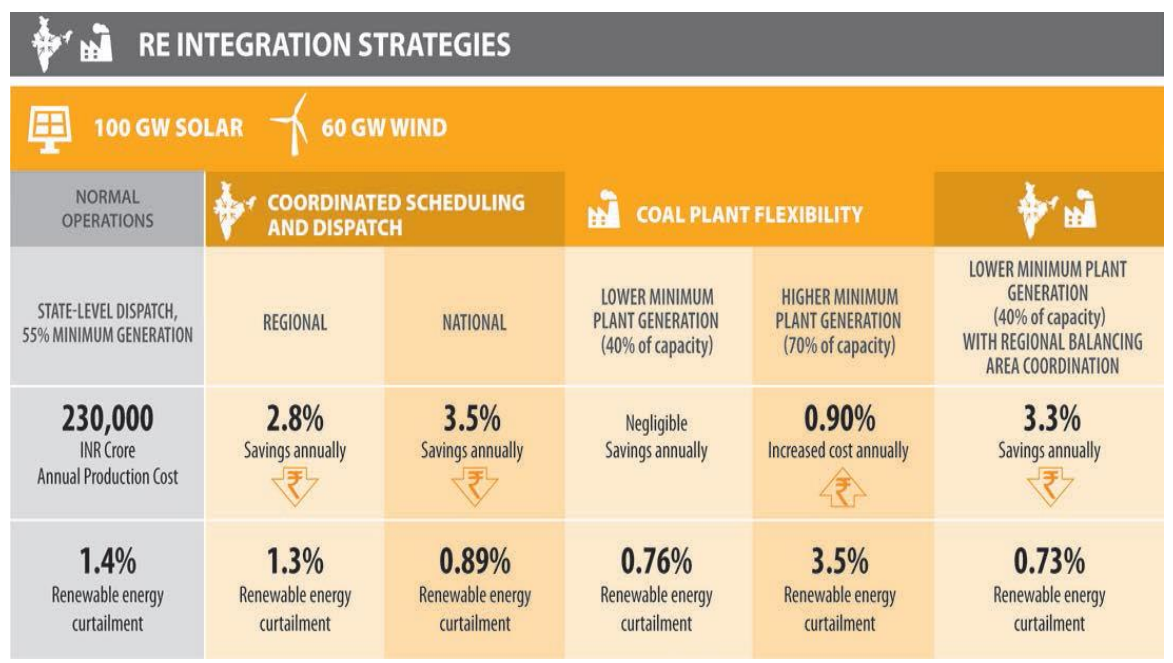

Figure5. Impact of RE integration strategies on production costs and RE curtailment

Greening the grid-renewable integration and sustainable energy (GTG-RISE) identified two approaches to better organize regional power markets to improve power-generation scheduling and dispatching to accelerate RE integration: a) model benefits and provide technical assistance to en large power-grid balancing areas from individual states to a regional or national market for day-a head (DAM) and real-time markets (RTM), b) automate the open-access approval process and reduce the lead time to conclude power exchange tradesin the national open access registry (NOAR). BESS in transmission and economic evaluation and quantification of BESS for ancillary market includes: a) implementation of various use cases of grid-connected BESS through softwareand hardware interventions, b) deployment of new controller unit, meters (at load sub-station \& RE plant) and workstations, c) installation of hardware switches/cable connections between new server and controller unit, d) software update of the existing supervisory control and data acquisition (SCADA) system e) enabling general packet radio services (GPRS) communication link between meters located at load point and solar PV, and f) use of software modelling tool for assessing impact of BESS inproviding primary and secondary regulation support [63].

Potential planning and policy actions to support RE integration includes national/state level planning to ensure sufficient interstate transmission, regulatory/policy guidelines to optimize generation and 
transmission buildouts with enhanced coordination of scheduling and dispatch between states and regions, flexible use of coal reserves/hydel resources depending on system requirements with suitable incentive mechanisms, development of time oriented tariff structure ensuring optimized production costs through supporting simulation softwares, flexibilble power purchase agreements for RE to limit financial risks for stakeholders with enough load/generation forecasting tools.

Energy transition in India will be a reality, by ensuring carbon-negative future to protect the environment by reducing $\mathrm{CO}_{2}$ emissions, reducing the import of fossil fuels and by creating climate resilient renewable infrastructure. GoI also made lot of initiatives and reforms related to land issues for RPG projects, imposing basic customs duty on balance of systems cost, developing core competency in semiconductor manufacturing, subsidizing solar manufacturing sector, reducing the cost of capital, providing loans, and financial support to the state governments to boost investor confidence [64].

\section{CONCLUSION}

India's global renewable energy leadership can be achieved through by setting RE target of $450 \mathrm{GW}$ by 2030 , building action evidence for reforms, adopting to innovations and market-based approach. This paper explores the impact of high penetration of RE on the system planning methodologies and its effective integration approaches. As the RE penetration level rise, its system performance characteristics similar to those of traditional generators should be evolved after a careful examination of standards, policies, and incentives along with the development of smart inverters and control methodologies. Policy and regulatory frameworks are needed to enable cost-effective investments and system operations for the dedicated renewable energy infrastructure through regulatory peer to peer partnerships among states, system operators, partnerships and private segment engagement. This approach will allow utilities, project developers and financing institutions to mobilize necessary expertise and fundingto resolve issues related to land use, electricity prices, quality of supply, emissions, and creation of domestic jobs in the renewable energy sector.

\section{ACKNOWLEDGMENT}

This work is supported by Indo-Sri Lanka Joint Research Program by department of science andtechnology (DST), Government of India and Ministry of Science, technology andresearch (MSTR), Government of Sri Lanka, through grant in aids DST: 14.00.31.14.60.798.60.3425 and MSTR/TR/AGR/3/02/13 respectively.

\section{REFERENCES}

[1] N. Nikolaev, K. Gerasimov, Y. Rangelov, and K. Gerasimov, "An algorithm for assessment of the impact of renewable energy sources on the power flow of the electric power system," 12th International Conference on Environment and Electrical Engineering, 2013, pp. 169-174, doi: 10.1109/eeeic.2013.6549611.

[2] T. Wang, T. Bi, H. Wang, and J. Liu, "Decision tree based online stability assessment scheme for power systems with renewable generations," in CSEE Journal of Power and Energy Systems, vol. 1, no. 2, pp. 53-61, June 2015, doi: 10.17775/CSEEJPES.2015.00019.

[3] P. Ju, H. Li, X. Pan, C. Gan, Y. Liu, and Y. Liu, "Stochastic Dynamic Analysis for Power Systems Under Uncertain Variability," in IEEE Transactions on Power Systems, vol. 33, no. 4, pp. 3789-3799, July 2018, doi: 10.1109/TPWRS.2017.2777783.

[4] J. Zheng, Y. Kou, M. Li, and Q. Wu, "Stochastic optimization of cost-risk for integrated energy system considering wind and solar power correlated," Journal of Modern Power System and Clean Energy.vol. 7, no. 6, pp. 1472-1483, 2019, doi: 10.1007/s40565-019-0519-4.

[5] J. Tao, M. Umair, M. Ali, and J. Zhou, "The impact of Internet of Things supported by emerging 5G in power systems: A review," in CSEE Journal of Power and Energy Systems, vol. 6, no. 2, pp. 344-352, June 2020, doi: 10.17775/CSEEJPES.2019.01850.

[6] S. Jiang, C. Wan, C. Chen, E. Cao, and Y. Song, "Distributed photovoltaic generation in the electricity market: status, mode and strategy," in CSEE Journal of Power and Energy Systems, vol. 4, no. 3, pp. 263-272, September 2018, doi: 10.17775/CSEEJPES.2018.00600.

[7] F. Allella, E. Chiodo, G. M. Giannuzzi, D. Lauria, and F. Mottola, "On-Line Estimation Assessment of Power Systems Inertia With High Penetration of Renewable Generation,” in IEEE Access, vol. 8, pp. 62689-62697, 2020, doi: 10.1109/ACCESS.2020.2983877.

[8] T. G. Hlalele, R. M. Naidoo, J. Zhang, and R. C. Bansal, "Dynamic Economic Dispatch With Maximal Renewable Penetration Under Renewable Obligation," in IEEE Access, vol. 8, pp. 38794-38808, 2020, doi: 10.1109/ACCESS.2020.2975674 
[9] O. Lennerhag, G. Pinares, M. H. J. Bollen, G. Foskolos, and T. Gafurov, "Performance indicators for quantifying the ability of the grid to host renewable electricity production," CIRED-Open Access Proceedings Journals, 2017, vol. 2017, no. 1, pp. 792-795, doi: 10.1049/oap-cired.2017.0178.

[10] A. Asadinejad, K. Tomsovic, and C. Chen, "Impact of residential customer classification on demand response results under high renewable penetration," 2017 IEEE Power \& Energy Society General Meeting, 2017, pp. 1-5, doi: 10.1109/PESGM.2017.8274062.

[11] E. Vilchez and J. Stenzel, "Impact of renewable energy generation technologies on the power quality of the electrical power systems," 22nd International Conference and Exhibition on Electricity Distribution (CIRED 2013), 2013, pp. 1-4, doi: 10.1049/cp.2013.0791.

[12] M. Q. Duong, N. T. Nam Tran, G. N. Sava, and M. Scripcariu, "The impacts of distributed generation penetration into the power system," 2017 International Conference on Electromechanical and Power Systems (SIELMEN), 2017, pp. 295-301, doi: 10.1109/SIELMEN.2017.8123336.

[13] M. Perdue and R. Gottschalg, "Energy yields of small grid-connected photovoltaic system: effects of component reliability and maintenance," IET Renew. Power Generation, vol. 9, no.5, pp. 432-437, 2015, doi: 10.1049/ietrpg.2014.0389.

[14] N. Voulis, M. Warnier, and F. M. T. Brazier, "The case for coordinated energy storage in future distribution grids," CIRED-Open Access Proceedings Journal, 2017, no. 1, pp. 2028-2031, doi: 10.1049/oap-cired.2017.0558

[15] Y. Sun, Z. Zhao, M. Yang, D. Jia, W. Pei, and B. Xu, "Overview of energy storage in renewable energy power fluctuation mitigation," in CSEE Journal of Power and Energy Systems, vol. 6, no. 1, pp. 160-173, March 2020, doi: 10.17775/CSEEJPES.2019.01950.

[16] W. Wangdee, "Reliability Impact of intermittent renewable energy source integration into power system," 2014 International Electrical Engineering Congress (iEECON), 2014, pp. 1-4, doi: 10.1109/iEECON.2014.6925977.

[17] X. Chen, M. B. Mcelroy, Q. Wu, Y. Shu, and Y. Xue, "Transition towards higher penetration of renewables: an overview of interlinked technical, environmental and socio-economic challenges," J. Mod. Power Syst. Clean Energy, vol. 7, no. 1, pp. 1-8, 2019, doi: 10.1007/s40565-018-0438-9.

[18] J. Meyer, A. M. Blanco, S. Rönnberg, M. Bollen, and J. Smith, "CIGRE C4/C6.29: survey of utilities experiences on power quality issues related to solar power," CIRED-Open Access Proceedings Journal, no. 1, pp. 539-543, 2017, doi: 10.1049/oap-cired.2017.0456.

[19] Q. Zhao, P. Wang, L. Goel, and Y. Ding, "Impacts of renewable energy penetration on nodal price and nodal reliability in deregulated power system," 2011 IEEE Power and Energy Society General Meeting, 2011, pp. 1-6, doi: 10.1109/PES.2011.6039340.

[20] S. Hu, Y. Xiang, X. Zhang, J. Liu, R. Wang, and B. Hong, "Reactive power operability of distributed energy resources for voltage stability of distribution networks," in Journal of Modern Power Systems and Clean Energy, vol. 7, no. 4, pp. 851-861, July 2019, doi: 10.1007/s40565-018-0484-3.

[21] V. Ritik, K. V. Vidyanandan, and N. Pal, "Growing share of wind power in the powersystem and its impacts on frequency regulation," 2nd IEEE International Conference on Recent Trends in Electronics, Information \& Communication Technology (RTEICT), 2017, pp. 188-194, doi: 10.1109/RTEICT.2017.8256583.

[22] D. L. Hau Aik and G. Andersson, "Impact of renewable energy sources on steady-state stability of weak AC/DC systems," in CSEE Journal of Power and Energy Systems, vol. 3, no. 4, pp. 419-430, Dec. 2017, doi: 10.17775/CSEEJPES.2016.01840.

[23] T. Aziz and N. Ketjoy, "PV Penetration Limits in Low Voltage Networks and Voltage Variations," in IEEE Access, vol. 5, pp. 16784-16792, 2017, doi: 10.1109/ACCESS.2017.2747086.

[24] T. Aziz and N. Ketjoy, "Enhancing PV Penetration in LV Networks Using Reactive Power Control and On Load Tap Changer With Existing Transformers," in IEEE Access, vol. 6, pp. 2683-2691, 2018, doi: 10.1109/ACCESS.2017.2784840.

[25] J. Gao, B. Han, C. Xu, L. Zhang, G. Li, and K. Wang, "Zonotope-based quantification of the impact of renewable power generation on hybrid AC/DC distribution system," The Journal of Engineering, vol. 16, pp. 2493-2499, 2019, doi: 10.1049/joe.2018.8520.

[26] T. S. Ustun, J. Hashimoto, and K. Otani, "Impact of Smart Inverters on Feeder Hosting Capacity of Distribution Networks," in IEEE Access, vol. 7, pp. 163526-163536, 2019, doi: 10.1109/ACCESS.2019.2952569.

[27] J. Matevosyan et al.., "Grid-Forming Inverters: Are They the Key for High Renewable Penetration?," in IEEE Power and Energy Magazine, vol. 17, no. 6, pp. 89-98, Nov.-Dec. 2019, doi: 10.1109/MPE.2019.2933072.

[28] B. Kroposki et al.., "Achieving a 100\% Renewable Grid: Operating Electric Power Systems with Extremely High Levels of Variable Renewable Energy," in IEEE Power and Energy Magazine, vol. 15, no. 2, pp. 61-73, MarchApril 2017, doi: 10.1109/MPE.2016.2637122.

[29] J. Sun et al.., "Renewable energy transmission by HVDC across the continent: system challenges and opportunities," in CSEE Journal of Power and Energy Systems, vol. 3, no. 4, pp. 353-364, Dec. 2017, doi: 10.17775/CSEEJPES.2017.01200.

[30] F. Blaabjerg, Y. Yang, D. Yang, and X. Wang, "Distributed Power-Generation Systems and Protection," in Proceedings of the IEEE, vol. 105, no. 7, pp. 1311-1331, July 2017, doi: 10.1109/JPROC.2017.2696878.

[31] J. Cárdenas and D. Menéndez, "Internet of things: how the electrical grid can be controlled and managed in other dimensions," 14th International Conference on Developments in Power System Protection (DPSP 2018) Journal of Engineering, 2018, no.15, pp. 918-923, doi: 10.1049/joe.2018.0194.

[32] D. Remon, C. A. Cañizares, and P. Rodriguez, "Impact of 100-MW-scale PV plants with synchronous power controllers on power system stability in northern Chile," IET Generation, Transmission and Distribution, vol. 11, no. 11, pp. 2958-2964, 2017, doi: 10.1049/iet-gtd.2017.0203. 
[33] Y. Guo, S. Li, C. Li, and H. Peng, "Short-Term Reliability Assessment for Islanded Microgrid Based on TimeVarying Probability Ordered Tree Screening Algorithm," in IEEE Access, vol. 7, pp. 37324-37333, 2019, doi: 10.1109/ACCESS.2019.2905001.

[34] J. Johnson, J. Quiroz, R. Concepcion, F. W. Bernal, and M. J. Reno, "Power system effects and mitigation recommendations for DER cyber attacks," IET Cyber Physical Systems: Theory \& Applications, vol. 4, no. 3, pp. 240-249, 2019, doi: 10.1049/iet-cps.2018.5014.

[35] A. L. Figueroa-Acevedo et al.., "Visualizing the Impacts of Renewable Energy Growth in the U.S. Midcontinent," in IEEE Open Access Journal of Power and Energy, vol. 7, pp. 91-99, 2020, doi: 10.1109/OAJPE.2020.2967292.

[36] Feng, B. Zeng, D. Zhao, G. Wu, Z. Liu, and J. Zhang, "Evaluating Demand Response Impacts on Capacity Credit of Renewable Distributed Generation in Smart Distribution Systems," in IEEE Access, vol. 6, pp. 14307-14317, 2018, doi: 10.1109/ACCESS.2017.2745198.

[37] S. Fan, Z. Li, Z. Li, and G. He, "Evaluating and Increasing the Renewable Energy Share of Customers' Electricity Consumption," in IEEE Access, vol. 7, pp. 129200-129214, 2019, doi: 10.1109/ACCESS.2019.2940149.

[38] B. Liang, W. Liu, L. Sun, Z. He, and B. Hou, "An Aggregated Model for Energy Management Considering Crowdsourcing Behaviors of Distributed Energy Resources," in IEEE Access, vol. 7, pp. 145757-145766, 2019, doi: 10.1109/ACCESS.2019.2945288.

[39] T. S. Ustun and Y. Aoto, "Analysis of Smart Inverter's Impact on the Distribution Network Operation," in IEEE Access, vol. 7, pp. 9790-9804, 2019, doi: 10.1109/ACCESS.2019.2891241.

[40] P. Westacott and C. Candelise, "Assessing the impacts of photovoltaic penetration across an entire low-voltage distribution network containing 1.5 million customers," IET Renewable Power Generation, vol. 10, no. 4, pp. 460466, 2016, doi:10.1049/iet-rpg.2015.0535.

[41] S. Lupo, M. Ruppert, V. Slednev, and A. E. Kiprakis, "Analysing the effect of increasing renewable capacities in Great Britain on the regional allocation and wholesale prices," CIRED-Open Access Proceedings Journal, no. 1, pp. 2082-2086, 2017, doi: 10.1049/oap-cired.2017.1118.

[42] X. Liu, Y. Liu, J. Liu, Y. Xiang, and X. Yuan, "Optimal planning of AC-DC hybrid transmission and distributed energy resource system: Review and prospects," in CSEE Journal of Power and Energy Systems, vol. 5, no. 3, pp. 409-422, Sept. 2019, doi: 10.17775/CSEEJPES.2019.00540.

[43] W. Wei, D. Wu, Z. Wang, S. Mei, and J. P. S. Catalão, "Impact of Energy Storage on Economic Dispatch of Distribution Systems: A Multi-Parametric Linear Programming Approach and its Implications," in IEEE Open Access Journal of Power and Energy, vol. 7, pp. 243-253, 2020, doi: 10.1109/OAJPE.2020.3006828.

[44] Rena Kuwahata, Peter Merk, Tatsuya Wakeyama, Dimitri Pescia, Steffen Rabe, Shota Ichimura, "Renewables integration grid study for the 2030 Japanese power system", IET Renewable Power Generation Vol. 14, Iss. 8, pp. 1249-1258, 2020. https://doi.org/10.1049/iet-rpg.2019.0711.

[45] B. Jie, T. Tsuji, and K. Uchida, "Impact of renewable energy balancing power in tertiary balancing market on Japanese power system based on automatic generation control standard model,", The Journal of Engineering, vol. 2019, no. 18, pp. 4760-4763, 2019, doi: 10.1049/joe.2018.9301.

[46] I. Boukhechem, A. Boukadoum, L. Boukelkoul, H. E. Medouce, and R. Lebied, "New control scheme for synchronizationof a photovoltaic system to a three-phase grid to attenuate the harmonics of currents caused by distorted grid voltage," International Journal ofApplied Power Engineering (IJAPE), vol. 9, no. 3, pp. 256-266. 2020, doi: 10.11591/ijape.v9.i3.pp256-266.

[47] P. A. G. M. Amarasinghe, S. K. Abeygunawardane, and C. Singh, "Kernel Density Estimation Based TimeDependent Approach for Analyzing the Impact of Increasing Renewables on Generation System Adequacy," in IEEE Access, vol. 8, pp. 138661-138672, 2020, doi: 10.1109/ACCESS.2020.3012406.

[48] Q. Huang, X. Wang, J. Fan, X. Zhang, Y. Wang, "Reliability and economy assessment of offshore wind farms," The Journal of Engineering, no. 16, pp. 1554-1559, 2019, doi: 10.1049/joe.2018.8472.

[49] Z. Chen, "Investigating the impact of distributed energy resources on market power of strategic utility corporation," IET Energy Systems Integration, vol. 1, no.2, pp. 97-103, 2019, doi: 10.1049/iet-esi.2018.0029

[50] M. Krpan and I. Kuzle, "Introducing low-order system frequency response modelling of a future power system with high penetration of wind power plants with frequency support capabilities," IET Renewable Power Generation, vol. 12, no.13, pp. 1453-1461, 2018, doi: 10.1049/iet-rpg.2017.0811.

[51] D. S. Kumar, A. Sharma, D. Srinivasan, T. Reindl, "Impact analysis of large power networks with high share of renewables in transient conditions", IET Renewable Power Generation, vol. 14, no. 8, pp. 1349-1358, 2020, doi: 10.1049/iet-rpg.2019.1224.

[52] G. Liu, S. Azizi, M. Sun, M. Popov, and V. Terzija, "Performance of out-of-step tripping protection under renewable integration,” The Journal of Engineering, no.15, pp. 1216-1222, 2018, doi: 10.1049/joe.2018.0180.

[53] Swati Bhamu and Terlochan Singh Bhatti, "State-space modelling of an interconnected system of renewable energy sources and grid for rural electrification", IET Energy Systems Integration, vol. 1, no. 2, pp. 74-87, 2019, doi: 10.1049/iet-esi.2018.0048.

[54] Y. Hirase, "Guidelines for required grid-supportive functions in grid-tied inverters with distributed energy resources," IET Energy Systems Integration, vol. 1, no. 4, pp. 236-245, 2019, doi: 10.1049/iet-esi.2019.0022.

[55] L. Wang, M. Yuan, F. Zhang, X. Wang, L. Dai, and F. Zhao, "Risk Assessment of Distribution Networks Integrating Large-Scale Distributed Photovoltaics," in IEEE Access, vol. 7, pp. 59653-59664, 2019, doi: 10.1109/ACCESS.2019.2912804. 
[56] S. Su, Y. Hu, L. He, K. Yamashita, and S. Wang, "An Assessment Procedure of Distribution Network Reliability Considering Photovoltaic Power Integration," in IEEE Access, vol. 7, pp. 60171-60185, 2019, doi: 10.1109/ACCESS.2019.2911628.

[57] J. Bebic, "Power system planning: emerging practices suitable for evaluating the impact of high-penetration photovoltaics,"National Renewable Energy Lab. (NREL), Feb. 2008, doi: 10.2172/924647.

[58] F. Katiraei and J. R. Agüero, "Solar PV Integration Challenges," in IEEE Power and Energy Magazine, vol. 9, no. 3, pp. 62-71, May-June 2011, doi: 10.1109/MPE.2011.940579.

[59] R. Seguin, J. Woyak, D. Costyk J. Hambrick, and B. Mather, High-Penetration PV Integration Handbook for Distribution Engineers, Technical Report,National Renewable Energy Lab. (NREL), Golden, CO, USA, Jan. 2016.

[60] Central electricity authority. Accessed: Sep. 15, 2021. [Online]. Available: http://cea.nic.in/reports/monthly/installedcapacity/2021/.

[61] India Renewable Integration Study Report. Accessed: may 01, 2020. [Online]. Available: https://posoco.in/reports/india-renewable-integration-study-report/.

[62] India Renewable Integration Study. Accessed. May 01, 2020. [Online]. Available: https://www.nrel.gov/analysis/india-renewable-integration-study.html/.

[63] USAID and Ministry of Power Government of India, "Excerpts from Transforming India's Power Landscape," in National Confreence on Large-Scale Integration of Renewable Energy in India, US-India Clean Energy Partnership under Greening the Grid Program, August 24-25, 2021. 